\title{
INTRODUCTION: \\ TRANSCENDENTAL PHILOSOPHY AND PHENOMENOLOGY
}

The relationship between the heritage of Kantian transcendental philosophy and phenomenology (Husserlian or post-Husserlian) is undoubtedly manifold. Not only Husserl was not originally moved by a transcendental interrogation in the elaboration of his idea of phenomenology, but his attitude towards Kant's critical philosophy and towards a certain brand of Kantianism has always been polemical. The contributions of this special issue aim to evaluate and to confront Kant's and Husserl's comprehension of the transcendental in the light of several key questions: the articulation between categoriality and intuition; the architectonic place of imagination among the faculties; the challenge of naturalism; the foundation of the sciences of nature or that of mathematics; the transcendental ground of epistemology in general. The post-Husserlian posterity of the transcendental claims and interrogations within phenomenology is also taken into account by considering their critical developments and transformations in Maurice Merleau-Ponty and Eugen Fink.

Setting a general framework for these various analyses, Rosemary R. P. Lerner's paper "The Sense of the Transcendental in Kant and in Husserl" revisits the Kantian reform of the transcendental, which removes the term from its initial ontological horizon and inscribes it within an epistemological field pertaining to human knowledge. The author also examines Husserl's retrieval of the "transcendental", which broadens its reach far beyond the merely "speculative" or "theoretical" and allows it to encompass the whole field of human lived experiences (theoretical, practical, evaluative) and activities (cultural, scientific or simply rooted in everyday life).

Vedran Grahovac's contribution "The Tenacity of 'Vicious Circularity' in Kant and Husserl: On Transcendental Deduction and Categorial Intuition" detects and examines a "strategy of circularity" employed by Kant and Husserl in their treatment of categoriality, while focusing on the particular relation between transcendental and metaphysical deductions in Kant's Critique and on the problem of "epistemic foundationalism" raised by the Fundierung of categorial intuition in sensuous intuition in Husserl's Sixth Logical Investigation. Instead of regarding this circularity as a deficient 
and damaging occurrence in argumentation, the author highlights its fruitfulness for re-articulating the logic-ontology and founding-founded polarities.

For Azul Katz, the confrontation field between Kant and Husserl is the place that imagination and phantasy hold in their transcendental philosophies. Her paper "The Defiance of the Transcendental by Phantasy and Imagination in Husserl and Kant" recalls the key function of Kantian imagination within reason, both theoretical and practical, while exhibiting its true potential in the aesthetic domain, as productive imagination. It also emphasizes the fact that the crucial methodological function of phantasy for Husserl, in the intuition of essences or in empathy, should not lead to underestimate the specific, more autonomous, regimen of pure phantasy.

With Jean-Daniel Thumser's paper « Le transcendantal et le naturalisme: Une relecture de Kant et Husserl » the inquiry shifts to epistemological issues, while dealing with the problem of a naturalization of the transcendental. In this perspective, the pathos of a priori knowledge is counterbalanced by the firm orientation towards the empirical, which demands to take into consideration the mundane and embodied condition of subjectivity. If one can undoubtedly find the seeds of a "phenomenological naturalism" in Husserl, the author goes even further and identifies a prefiguration and resource for naturalizing phenomenology in Kant himself.

The horizon of naturalism is also visible in Francesco Pisano's contribution "The Material Residue. Kant and Husserl on an Aspect of the Transcendental Foundation of the Science of Nature", which deals with the problems raised by the "facticity of nature" in respect to the particular status of transcendental subjectivity, regarded as temporal. If facticity and ideality come together within the transcendental life of subjectivity and allow resolving the discrepancy between form and matter, the transcendental foundation of the science of nature (as a particular variant of the a priori foundation of our ordinary knowledge of facts) encompasses itself a factual, non-formalizable element.

The epistemological ambition of transcendental philosophy is once again at stake in Philipp Berghofer's paper "New Ways to Transcendental Phenomenology: Why Epistemology Must be a Descriptive and Eidetic Study of Consciousness", which aims to show how current debates in analytic epistemology can unexpectedly help to motivate transcendental phenomenology and even plead for a transcendental grounding of epistemology in general. If, undoubtedly, Husserl's project of transcendental phenomenology is intended to reveal and elucidate the ultimate epistemological principles (rather than to provide infallible justification), and mobilizes for this purpose an eidetic, a priori, description structures of consciousness, one has a solid ground to claim that the study of consciousness in a non-empirical descriptive and eidetic 
fashion, for epistemological reasons, can be considered to be a way to transcendental phenomenology.

In "Rethinking Spatiotemporal Extension: Husserl's Contribution to the Debate on the Continuum Hypothesis", Claudio Tarditi aims to demonstrate the relevance of Husserl's phenomenology for the debate around Cantor's continuum hypothesis, and shows to what extent the mathematicians that consider the continuum conjecture as relevant for a scientific description of reality and for its philosophical foundation have been inspired by Husserl: it is the case of Weyl and Gödel himself, though both progressively abandoned phenomenology. Yet, the author intends to prove that Husserl's account of the continuum, developed in different ways by Weyl and Gödel, remains "the unique radical attempt to found mathematical formalization on intuition". Accordingly, transcendental phenomenology can still play a relevant role in current debates about the foundation of mathematics.

The promise of transcendental philosophy finds, as we can see, a valuable field for proving its fertility in epistemology and in respect to the task of the foundation of science. But is its philosophical posterity as favourable to its development and longevity? The case of Merleau-Ponty is a particularly revealing one, and two contribution take up its exploration. Firstly, Sebastjan Vörös and Timotej Prosen, in "Bearing One's Shadow: The Architecture of the Transcendental from Kant, through Husserl, to Merleau-Ponty", reactivate the question of a naturalization of phenomenology, while showing that this question is sensibly altered between Kant's "transcendentalism of faculties", "Husserl's "transcendentalism of pure consciousness" and Merleau-Ponty's "transcendentalism of the flesh". By taking into account these variations, it becomes possible to provide a notion of the transcendental that does not evacuate or exclude the "truth of naturalism". Secondly, Don Beith's paper "Nature as Expressive Synthesis: The Sensible Awakening of the Transcendental between Kant, Husserl and Merleau-Ponty" finds its starting point in the tension between activity and passivity within the nature of consciousness, in order to present the passivity of consciousness as a form of synthesis that originates in our expressive bodily nature. The author grounds this claim by confronting the way Kant, Husserl and Merleau-Ponty specifically articulate a synthesis within sensibility and bodily affectivity.

An equally important challenge for transcendental phenomenology, in the immediate continuity of Husserl's work, has come from his assistant and collaborator Eugen Fink. In "Beyond the Genesis, Toward the Absolute. Eugen Fink's Architectonic Foundation of a Constructive Phenomenology between a Meta-Critic of Transcendental Experience and his own Project of a Dialectical Meontic", Giovanni Jan Giubilato examines the way Fink attempted to overcome what appeared to him as the incompleteness of 
Husserl's development of transcendental philosophy, through a solid "critic of the transcendental reason". But what prepared itself as a complement resulted ultimately in a shift towards a new kind of phenomenology, endowed with a "constructive" method. Furthermore, Fink's constructive phenomenology set in motion the development of his own meontic philosophy, elaborated in his private notes, in which the question of the "enworlding (Verweltlichung)" reveals not only the "ontological opacity of transcendental life", but also the insuperable difficulty of the task of a world-constitution.

Our choice of book reviews for this issue was also made in strict connection and accordance with this realm of problems related to transcendental philosophy. Firstly, Eric Beauron's review of the new French translation (due to Arnaud Pelletier) of Kant's Metaphysical Foundations of Natural Science (Vrin, 2017) allows focusing on the material donation of the objects of experience and interrogating the possibility to relate the empirical properties of the object to the universal principles grounded in the categories. The project of a metaphysics of nature, dealing with mundane, material bodies, can thus appear as the necessary and crucial continuation of the transcendental enterprise deployed in the Critique. Secondly, by giving an outline of Béatrice Longuenesse's book I, Me, Mine. Back to Kant, and Back Again (Oxford University Press, 2017), Claudia Serban revisits the Kantian account of the ego and the problem of naturalizing transcendental philosophy. Thirdly, Paul Slama's review of Chad Engelland's book: Heidegger's Shadow. Kant, Husserl, and the Transcendental turn (Routledge, 2017) looks into the interpretation of Heidegger as a transcendental philosopher and insists on the importance of understanding the role of intuition and that of affectivity when the relationship between phenomenology and Kant is at stake. Last but not least, Iulian Apostolescu's presentation of the collective volume edited by Sara Heinämaa, Mirja Hartimo and Timo Miettinen Phenomenology and the Transcendental (Routledge, 2014) gives an account of the way recent research has dealt with the question of knowing if, and in what fashion, the project of a transcendental phenomenology can still be defended and promoted as philosophically fertile today. Bringing new light into this challenging interrogation has also been one of the aims of the present issue.

We would like to express our gratitude to all contributing authors for their efforts to produce novel interpretative essays on the theme that has been proposed to them. Special thanks are also due to the editorial team of Horizon. Studies in Phenomenology for supporting and encouraging this project from its inception through all the phases of its realization.

Claudia SERBAN, Iulian APOSTOLESCU 